\title{
Morte súbita em vaca por ruptura de aneurisma aórtico
}

Erick Platiní Ferreira Souto; Maria Talita Soares Frade, Robério Gomes Olinda, Eldine Gomes Miranda Neto, Antônio Flávio Medeiros Dantas

Programa de Pós-Graduação em Medicina Veterinária, Hospital Veterinário, Centro de Saúde e Tecnologia Rural, Universidade Federal de Campina Grande (UFCG), Patos, PB, Brasil

*Autor correspondente

e-mail: erickplatini@gmail.com

\section{Resumo}

Aneurisma é uma dilatação patológica, localizada, de um segmento enfraquecido de um vaso sanguíneo. A principal consequência é a ruptura do vaso, que pode cursar com hemorragia intensa, choque hipovolêmico e morte súbita. 0 presente trabalho descreve um caso de morte súbita em vaca por ruptura de aneurisma aórtico. Foi encaminhada para necropsia no Laboratório de Patologia Animal da UFCG, em março de 2012, uma vaca adulta, sem raça definida, proveniente da zona rural do município de Patos, Paraíba, com histórico de timpanismo recidivante e morte súbita durante o translado para atendimento clínico no hospital veterinário. No exame externo do cadáver, observaram-se mucosas pálidas, retração do globo ocular e acentuada distensão da cavidade abdominal (timpanismo). Na necropsia, verificou-se grande quantidade de coágulos de sangue na cavidade torácica. Na aorta torácica ascendente havia dilatação saculiforme, com aproximadamente $20 \mathrm{~cm}$ de diâmetro, completamente preenchida por sangue coagulado. Na abertura do vaso havia ruptura em formato circular, medindo $4 \mathrm{~cm}$ de diâmetro, e comunicando as camadas íntima e média. 0 aneurisma causava compressão mecânica da porção torácica do esôfago, o qual apresentava área focal de necrose transmural. Na histopatologia do vaso afetado, observou-se perda da camada íntima, degeneração flocular, necrose e fragmentação de fibras elásticas da camada média. Em algumas secções, as fibras elásticas estavam desorganizadas, tortuosas e com perda da adesão, além de apresentarem áreas multifocais discretas de mineralização. 0 diagnóstico foi estabelecido com base nos dados clínicos e achados anatomopatológicos. A presença do aneurisma aórtico promovia compressão mecânica do esôfago, dificultando a eructação dos gases da fermentação ruminal e causando um quadro de timpanismo secundário crônico. Animais que desenvolvem aneurismas podem manifestar sinais clínicos secundários à compressão de estruturas próximas, mas, na maioria das vezes, são apenas encontrados mortos por ocasião da ruptura. 
Provavelmente, condições traumáticas ou estressantes durante o transporte do animal levaram à ruptura do aneurisma e consequente morte súbita por choque hipovolêmico. 0 desenvolvimento de aneurismas em bovinos é infrequente e são escassos os dados disponíveis na literatura científica. A deficiência de cobre tem sido implicada como causa de aneurismas em várias espécies animais, mas ainda não foi determinada relação com a espécie bovina. A síndrome de Marfan tem sido identificada como causa da formação de aneurismas em bovinos jovens, mas o caso aqui relatado ocorreu em um bovino adulto e não foram observadas outras alterações comuns à síndrome. Portanto, é difícil estabelecer a causa para a formação de aneurismas, mas a ruptura desses deve ser considerada no diagnóstico diferencial de morte súbita em bovinos. 